\title{
TURBIDITY RESPONSE TO DISCHARGE IN THE UPSTREAM REGION OF THE HITOTSUSE RIVER WATERSHED
}

\author{
Donny HARISUSENO ${ }^{1}$, Satoru SUGIO ${ }^{2}$, Jun NAKAMURA ${ }^{3}$, Chikashi DEGUCHI ${ }^{4}$, \\ and Mitsuhiro SEZAKI ${ }^{4}$ \\ ${ }^{1}$ Student member of JSCE, M.Eng., Graduate Student, System Engineering, University of Miyazaki \\ (Gakuenkibanadai-nishi 1-1, Miyazaki 889-2192, Japan) \\ 2 \\ Member of JSCE, Dr. of Eng., Professor, Dept. of Civil and Environmental Engineering, University of Miyazaki \\ 3 Engineer, Miyazaki Branch, Kyushu Electric Power Co.,Inc. (Tachibanadori 4, Miyazaki 880-8544, Japan) \\ ${ }^{4}$ Member of JSCE, Dr. of Eng., Assoc. Professor, Dept. of Civil and Environmental Eng., University of Miyazaki
}

\begin{abstract}
The objective of this study was to obtain a better understanding of high turbidity generation in the upstream region of the Hitotsuse River watershed, by focusing on analyzing the turbidity response to discharge in the river stream. This study revealed that there were 3 types of sources of turbid water in the study area, namely: Type 1 (Collapsed of mountainside), Type 2 (Outflow of collapsed soil), and Type 3 (Waterside erosion). This study proposed the Turbidity Discharge Ratio as means for detecting the problem of turbid water generation. The results showed that the Turbidity Discharge Ratio was fluctuate during 1994 - 2003. Turbidity Discharge Ratio was very high, slightly after the occurrence of heavy rainfall triggered by a typhoon. This study clarified that the Turbidity Discharge Ratio tended to decrease due to the lesser amounts of fine particles transported to the river and the cumulative discharge about $200 \times 10^{3} \mathrm{~m}^{3} / \mathrm{s}$ is required to reduce the Turbidity Discharge Ratio below 1 .
\end{abstract}

Key Words : Turbidity, source of turbid water, collapsed area, turbidity discharge ratio

\section{INTRODUCTION}

Problems of the turbid water generation and the prolongation of turbid period have occurred in the Hitotsuse River watershed and the Omaru River watershed $^{1)}$, which are located in the middle of Miyazaki Prefecture.

The Hitotsuse River watershed has, until recently, been perceived to be in a critical problem of turbid water propagation, resulting from the dam's construction. In the past years, several efforts had been already conducted to reduce the turbidity in the watershed. However, those were only concentrated in reducing turbidity in the stored water of reservoir. In this manner, concerning the reducing of high turbid water generation problem in the river should not only be focused in the reservoir, but it is also very important to manage and control the turbidity generation in the upstream region of watershed.

However, few studies concerning the generation of turbid water in the upstream region have been conducted before ${ }^{2), 3)}$. Since it is essential to obtain a better understanding of the generation of turbid water in the upstream region, this paper will focus on analyzing the turbidity response to discharge in the river stream in the upstream region of the watershed.

\section{RIVER BASIN CHARACTERISTICS}

\section{(1) Study area}

The Hitotsuse River watershed has a drainage area of $846 \mathrm{~km}^{2}$ and a river length of $91.1 \mathrm{~km}$. This study will focus on the upstream region of the watershed, which has a drainage area of $209.3 \mathrm{~km}^{2}$ and $25.6 \mathrm{~km}$ of river length (Fig.1). Analyzing from the numeric data with $50 \mathrm{~m}$ mesh elevation made by Geographical Survey Institute ${ }^{4)}$, the topography slope of the study area is mainly characterized by a steeply incised valley with slopes ranging from 0.20 to 0.71 . 


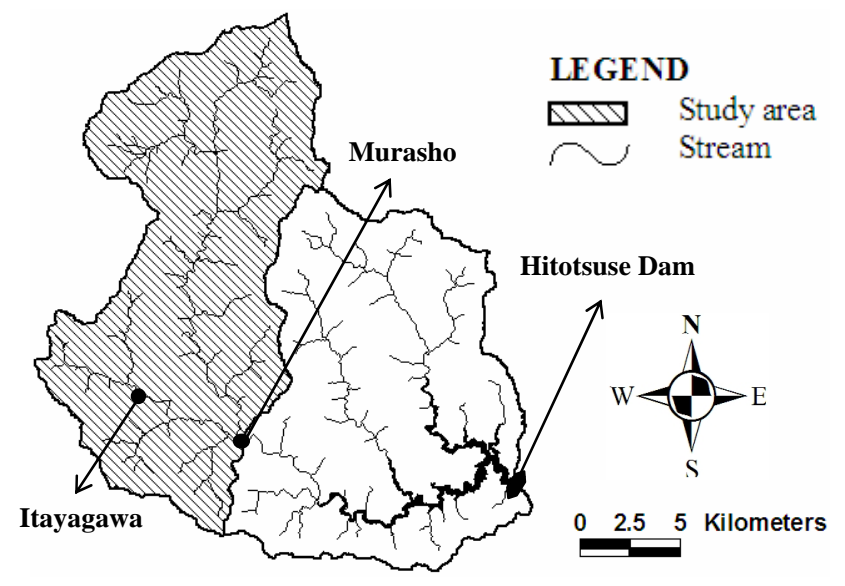

Fig.1 Study area.

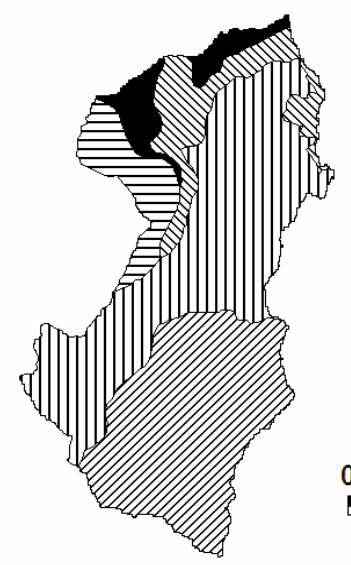

\section{LEGEND}

Geology

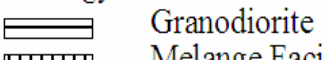

एسIس Melange Facies

AIIIIV Mudstone

Sandstone

WIIII Sandstone mudstone

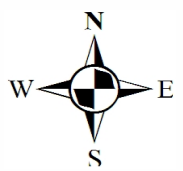

02.55 Kilometers

Fig.2 Geology type distribution in the study area.

\section{(2) Geological features}

The geology of the study area ${ }^{5)}$ is dominated by 3 types of geological strata, those are sandstone mudstone which cover approximately $33.4 \%$ of study area, mudstone (10.4\% coverage), sandstone (6.4\% coverage), granodiorite ( $7.9 \%$ coverage) and melange facies (41.9\% coverage). These types of geological strata are generally finely grained and most likely susceptible to be eroded. This will influence the turbid water generation. The geological distribution within the study area is shown in Fig.2.

\section{(3) Top soil distribution}

Major parts of the study area are mainly dominated by brown forest soil which covers $54.2 \%$ of the total study area and dry forest soil which occupies $37.8 \%$ of the study area.

\section{(4) Location of hydrometric station}

The rainfall and discharge data were measured at Murasho hydrometric station which was designed by Ministry of Economy, Trade, and Industry of Japan on November 1937 (Fig.1). On July 1990, the

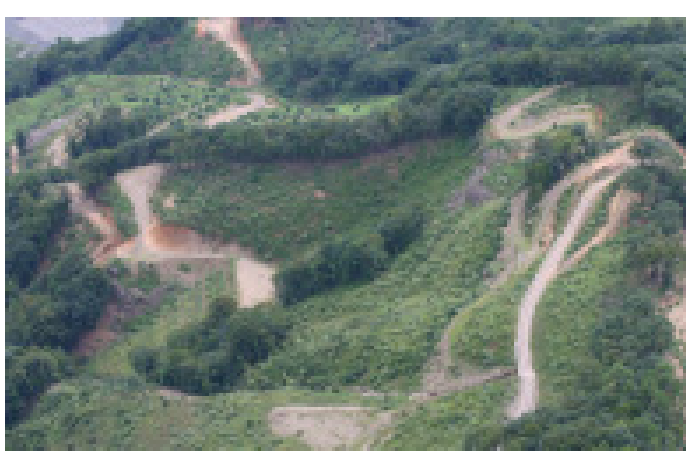

Fig.3 Forestry working passage (bad management forestry).

Table 1 Collapsed area in the study area.

\begin{tabular}{|c|c|}
\hline Period & Collapsed area $\left(\mathrm{km}^{2}\right)$ \\
\hline 2004 & 1.51 \\
2006 & 1.72 \\
\hline
\end{tabular}

HOKUTO-RIKAN MA-1601 turbidimeter was installed at the same place to measure turbidity in the river stream.

\section{(5) Forestry working passage}

Forestry working passages are a primary sediment source in forested watersheds ${ }^{6}$. Most of forestry working passages in the study area correlate with collapsed area occurrence, and become the main source of turbid water in the study area. Fig.3 shows forest working passages in the study area.

\section{(6) Collapsed area}

A collapsed area is caused by a combination of uncontrollable natural conditions (e.g. heavy rainstorms, earthquake, etc) and artificially altered landforms ${ }^{7}$. Collapsed area was recognized as the major source of the high turbidity generation in the river stream in the study area.

\section{(7) Change of collapsed area}

Analyses of the collapsed areas in this study were conducted by extracting land cover characteristic from satellite remote sensing. The land cover was classified by using SPOT images having the ground resolution of 10 by $10 \mathrm{~m}$. The observation dates of the SPOT images are taken on October 13, 2004 and February 3, 2006. Land cover was classified using the Maximum Likelihood Method. Fig.4 shows the distribution of collapsed area in the study area. The change of the collapsed area in the study area is displayed in Table 1. In the period 2004 to 2006, there was a significant increase of about $14 \%$ in total collapsed area. 


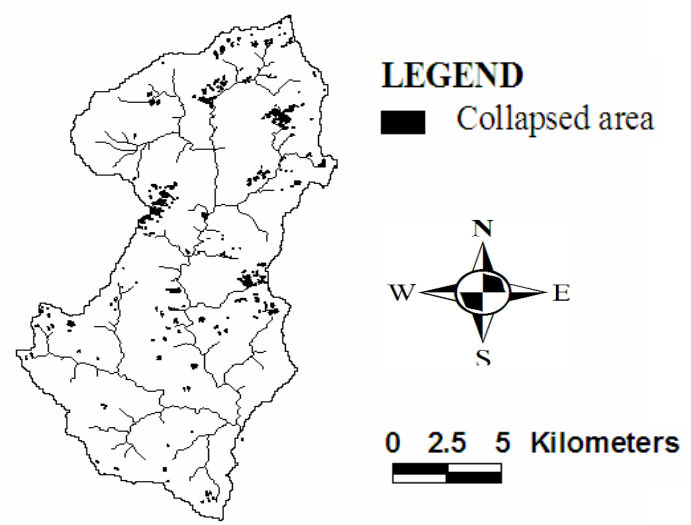

Fig.4 Distribution of collapsed areas in the study area.

Table 2 Maximum turbidity, daily rainfall, and hourly rainfall in each year of observation.

\begin{tabular}{|c|c|c|c|}
\hline Year & $\begin{array}{c}\text { Maximum } \\
\text { Turbidity (ppm) }\end{array}$ & $\begin{array}{c}\text { Daily Rainfall } \\
(\mathrm{mm} / \mathrm{day})\end{array}$ & $\begin{array}{c}\text { Hourly Rainfall } \\
(\mathrm{mm} / \mathrm{hr})\end{array}$ \\
\hline 1993 & 802.6 & 87 & 27 \\
1994 & 632.7 & 62 & 8 \\
1995 & 1079.9 & 99 & 19 \\
1996 & 947.2 & 242 & 31 \\
1997 & 1079.9 & 309 & 35 \\
1998 & 631.9 & 118 & 31 \\
1999 & 568.5 & 124 & 23 \\
2000 & 324.8 & 95 & 28 \\
2001 & 825.9 & 74 & 24 \\
2002 & 334 & 114 & 29 \\
2003 & 982.1 & 152 & 41 \\
2004 & 1079.9 & 331 & 38 \\
2005 & 1079.9 & 333 & 29 \\
2006 & 1079.9 & 113 & 31 \\
\hline
\end{tabular}

\section{TURBID WATER GENERATION}

Table 2 shows the annual maximum turbidity, daily rainfall, and hourly rainfall which were collected in the same time of observation. It seems that the high turbid water is always accompanied by high rainfall occurrence, however Table 2 indicates that the relationship between the turbidity and rainfall did not show a good relationship or it was unclear. Therefore, this study will focus on analyzing the turbidity in response to discharge in the river. An explanation for the occurrence of high turbidity is shown in Fig.5, which shows the relationship between turbidity and rainfall in Typhoon No. 16 in 2004 due to a large amount of collapsed areas which generated high turbidity in the upstream region of the watershed.

\section{(1) Sources of turbid water generation}

From the field investigation and turbidity measurements, the sources of turbid water generation in response to hydrological events in the

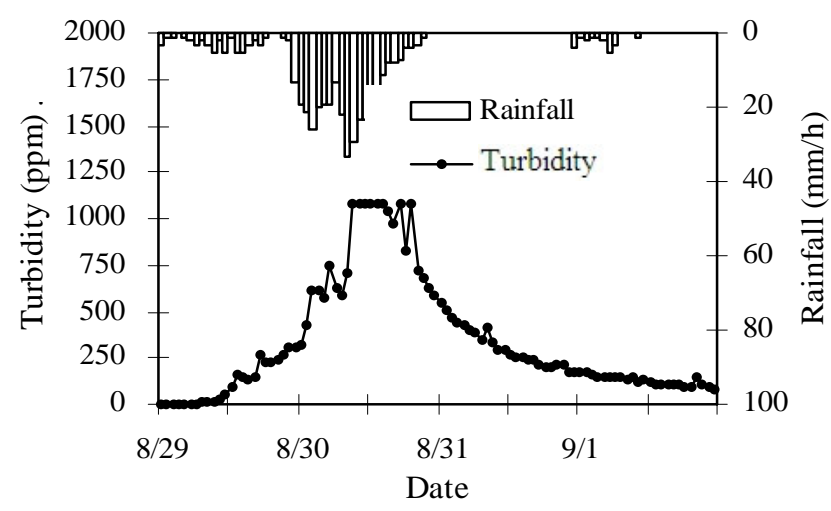

Fig.5 Turbidity-rainfall event in 2004.

Table 3 Sources of turbid water generation in the study area.

\begin{tabular}{|c|l|l|l|}
\hline Type & \multicolumn{1}{|c|}{ Configuration } & \multicolumn{1}{c|}{ Occasion } & \multicolumn{1}{|c|}{ Factor } \\
\hline 1 & Collapsed of mountainside & Instantaneous & Heavy rainfall \\
2 & Outflow of collapsed soil & Intermitten & Rainfall \\
3 & Waterside erosion & Continual & Stream flow \\
\hline
\end{tabular}

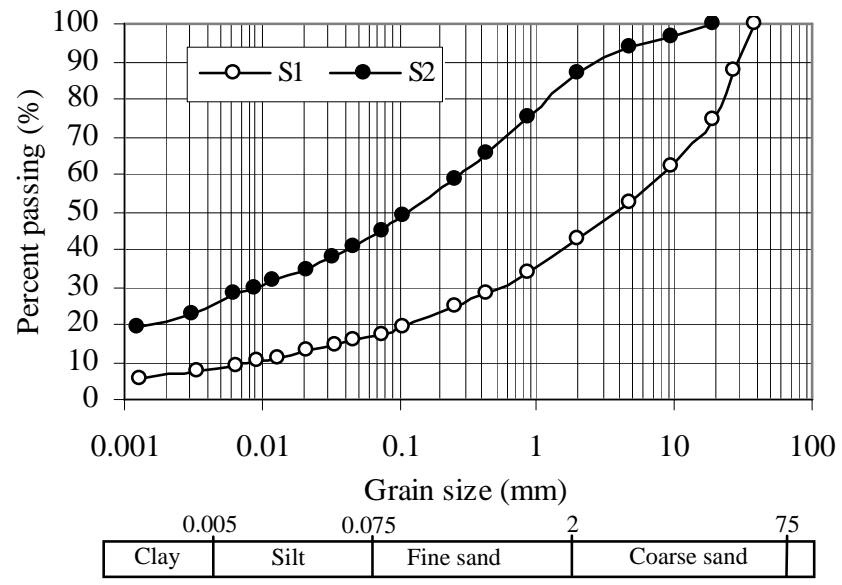

Fig.6 Soil size distribution of collapsed soil.

study area were presumed to be from 3 types, as shown in Table 3.

\section{A. Type 1 (Collapsed of mountainside)}

Type 1 expresses to the generation of turbid water due to the collapsed of mountainside. In certain circumstances where the collapsed soils from mountainside fall down into river channel, it will be transported by stream flow.

Fig.5 shows the response of turbidity peak to the heavy rainfall occurrence. During this time, there was a possibility that a considerable amount of collapsed soil, which contained a high percentage of fine particles (silt and clay), were eroded and routed down from the mountainside to the river channel. Fig.6 shows the soil size distribution of collapsed soil which was obtained 


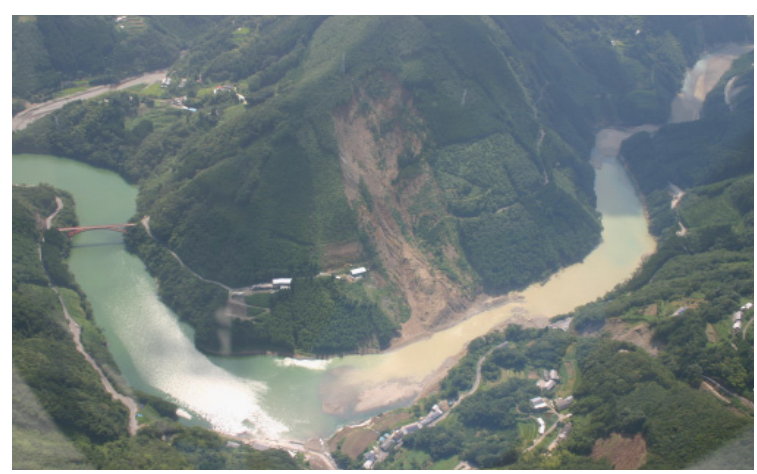

Fig.7 Collapsed area of mountainside (Type 1).

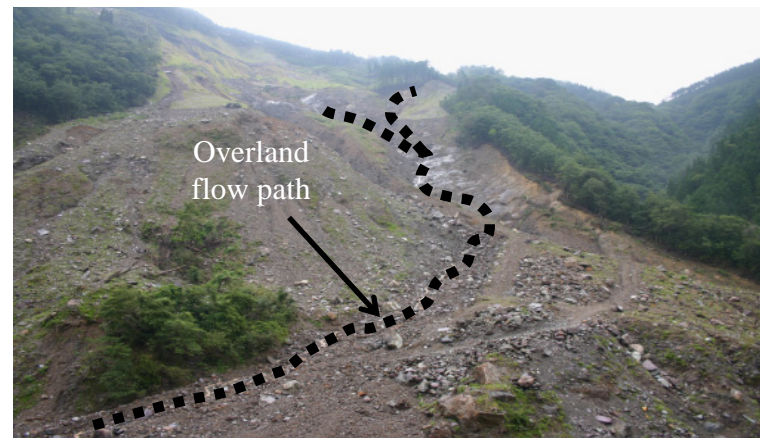

(a) Hillslope middle.

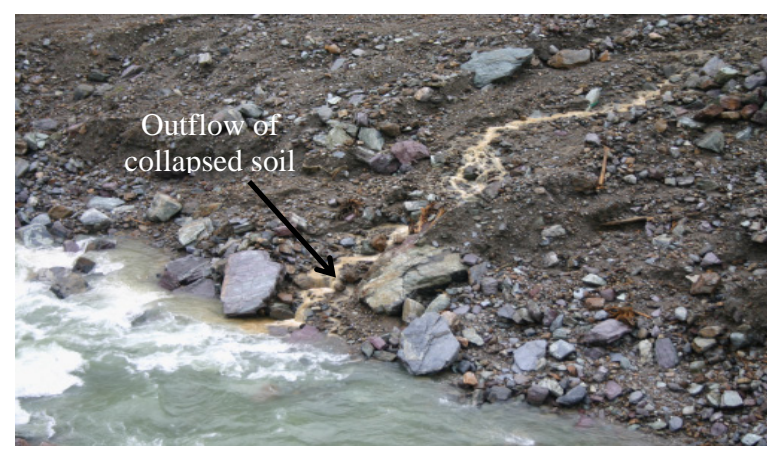

(b) Hillslope toe.

Fig.8 Source of turbid water from outflow of collapsed soil (Type 2).

from field investigation on July 27, 2007, at Itayagawa region (Fig.1). The top line (S-2) shows the soil distribution graphic for collapsed soil which contains a high percentage of silt and clay. The bottom line (S-1) contains of low percentage of silt and clay. The existence of the collapsed areas in the study area as shown in Fig.4 was evidence of the generation of turbid water in the river of the Type 1 . Fig.7 shows collapsed area of mountainside.

\section{B. Type 2 (Outflow of collapsed soil)}

Type 2 expresses the generation of turbid water

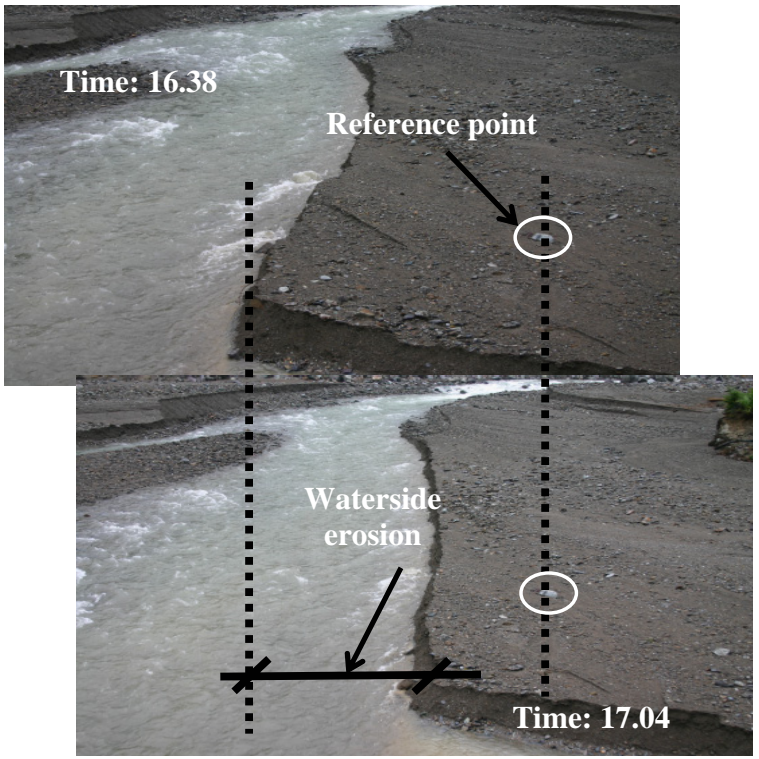

Fig.9 Source of turbid water from waterside erosion (Type 3).

due to the outflow of collapsed soil. The primary causal factor of source of turbid water in Type 2 is overland flow. In the case of numerous amounts of collapsed soil from the mountainside, some parts of the collapsed soil will be deposited somewhere on hillslope toe on their way before entering the river stream. These deposited of collapsed soil will become a potential source of turbid water in the high rainfall event, where overland flow which come from the surface of collapsed areas will run across the deposited soils and transport fine particles to the river stream. The rill and gully channel resulting from erosion process on the mountain hillslope will give a route for overland flow. The high rainfall which occurred after the slope failure events will cause turbid water of Type 2 and take place over a longer period of time. Therefore, Type 2 turbid water source generation plays an important role in the problem of turbid water prolongation in the river. The source of turbid water from Type 2 in the study area can be seen in Fig.8.

\section{Type 3 (Waterside erosion)}

Type 3 expresses the generation of turbid water due to waterside erosion. In this Type, stream flow becomes the driving factor of turbid water generation in the river. Normally, the duration of Type 3 will take place over a long period of time, as long as there is a flow in stream, and this process will continue all the time (continual), either there is rainfall event or not. In Type 1 , the collapsed soil transported by stream flow will be accumulated in somewhere in the 


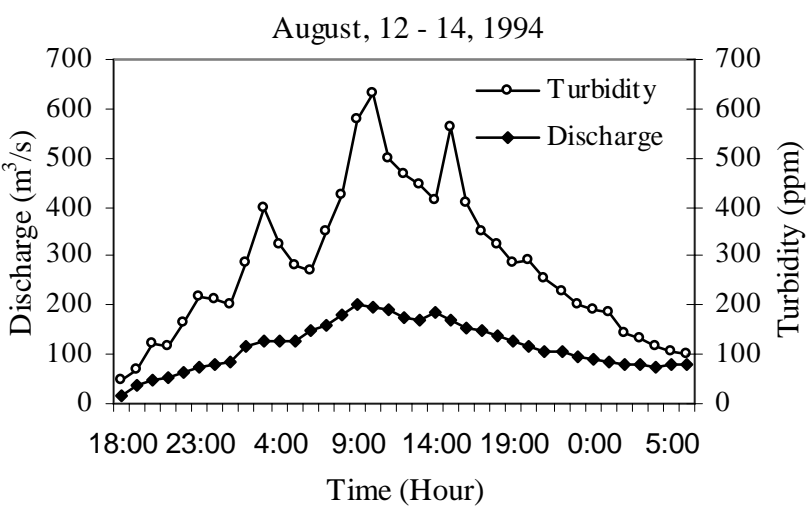

(a)

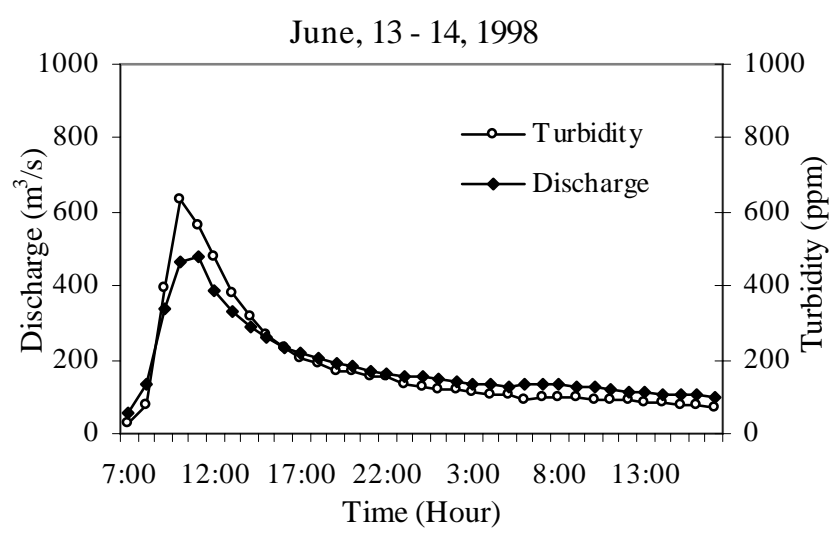

(b)

Fig.10 Turbidity-discharge events for selected periods.

downstream part. These accumulated soils, subsequently, will be transported again by stream flow to other parts in the downstream. These transportation and accumulation processes of fine particles in the river stream will take place continually. Type 3 is also the primary causal factor of the problem of turbid water prolongation in the river stream. Fig.9 shows the source of turbid water from Type 3.

\section{CHANGE OF TURBIDITY}

\section{(1) Definition of Turbidity Discharge Ratio}

Fig. 10 shows two turbidity-discharge events in different period used in this study. Fig.10 (a) was characterized by a higher of turbidity value than discharge on August 12 - 14, 1994, while Fig.10 (b) shows a similar value of turbidity and discharge on June 13 - 14, 1998. Those figures indicate an occurrence of the different response between turbidity and discharge. In order to express these different response phenomena, the Turbidity Discharge Ratio was proposed and defined as the ratio between the total amount of turbidity and total

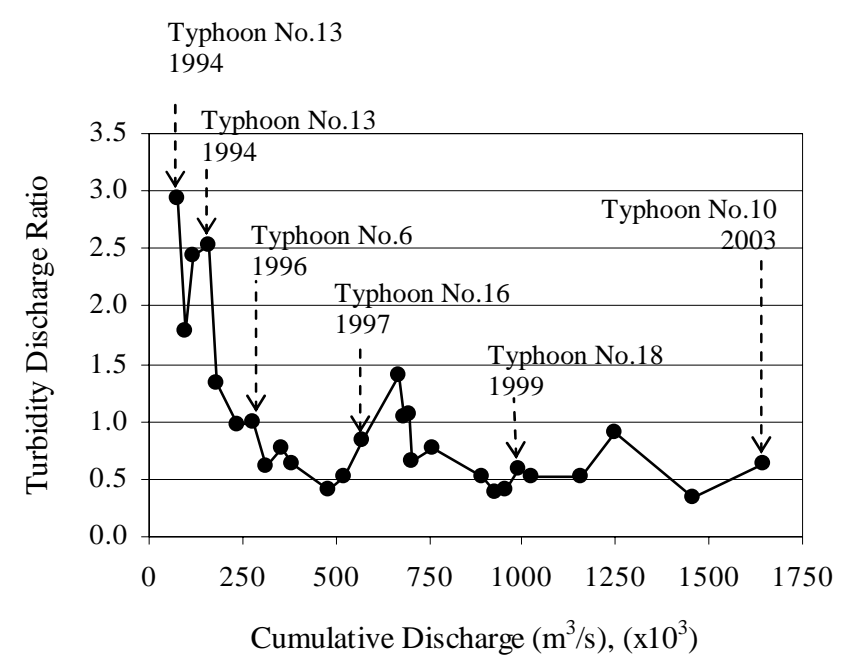

Fig.11 Result of Turbidity Discharge Ratio 1994 - 2003.

amount of discharge in a specific period of observation. The total amount of turbidity and discharge, in this case, represent the area of turbidity hydrograph and discharge hydrograph respectively, as shown in Fig.10. Fig.10 (a) shows a value of more than 1 of the Turbidity Discharge Ratio, while in Fig.10 (b) the value is nearly 1. This description clearly shows the change of turbidity in response to hydrological events.

\section{(2) Calculation of Turbidity Discharge Ratio}

The discharge and turbidity measurement data which are used in this study were collected during the period 1993 - 2006 at hourly intervals. The enormous typhoons on September 2 - 4, 1993 and August 29 - 31, 2004 caused a considerable amount of collapsed areas. There was a lack of measurements during September 1993 - March 1994, hence, 27 turbidity-discharge event records were selected during 1994 - 2003 to analyze the Turbidity Discharge Ratio due to the collapsed areas in 1993. From these serial data of turbidity and discharge, a selection of specific measurement periods was carried out by selecting only periods when the turbidity were higher than $100 \mathrm{ppm}$. After selecting the measurement periods of turbidity and discharge, the calculation of the summation of each turbidity and discharge in that period can be done, followed by the calculation of the Turbidity Discharge Ratio.

\section{(3) Discussion}

The result of the Turbidity Discharge Ratio in the study area over the period 1994 - 2003 as shown in Fig.11, depict the fluctuation of Turbidity Discharge Ratios from year to year, ranging from 2.93 to 0.33. Fig.11 shows that in the early period of observation (within April 4 - 
13, 1994), the Turbidity Discharge Ratio was very high (2.93). The height of the Turbidity Discharge Ratio during this period was due to a high percentage of silt and clay in the collapsed soil. The period of relatively high of Turbidity Discharge Ratios were occurred until $180 \times 10^{3} \mathrm{~m}^{3} / \mathrm{s}$ of cumulative discharge (June, 1995).

Within the period of cumulative discharge $230 \times 10^{3} \mathrm{~m}^{3} / \mathrm{s}$ to $1640 \times 10^{3} \mathrm{~m}^{3} / \mathrm{s}$ (July, 1995 to August, 2003), the fluctuation of Turbidity Discharge Ratio values are relatively stable, averaging 0.70 . Noted that, during this period, there were several large storms triggered by typhoon hazard which struck a part of Miyazaki, however, those typhoons didn't strike the study area. Therefore, a large amount of collapsed areas almost didn't occur in this period. Hence, within this period there are no significant contribution of high turbid water from Type 1 . Therefore, a cumulative discharge about $200 \times 10^{3} \mathrm{~m}^{3} / \mathrm{s}$ is required to reduce the Turbidity Discharge Ratio below 1 . The Type 2 and Type 3 play an important role in the fluctuation of turbidity in river stream in this period. Within this period, it can be said that there were no significant problems regarding with the generation of high turbid water in the river stream in the study area.

On September $4-6,2005$, there was a large storm events caused by a typhoon which struck the study area. The analyses from of SPOT images resulted from this study, showed that there was a significant increase in collapsed areas of about $14 \%$ as shown in Table 1. This typhoon event will be a reference for starting point of the next turbidity-discharge response.

The results of this study imply some recommendations regarding with the treatment management in the upstream region of the Hitotsuse River watershed, especially for minimizing sources of turbid water. The appropriate forestry management have to be applied to minimize the source of turbid water from Type 1 . As for Type 2 and Type 3, a better management on both hillslopes or riverside areas should be conducted.

\section{CONCLUSION}

The following results were obtained in this study:

1. Remote sensing analysis clarified that there was a significant increase in collapsed area of $14 \%$ in the upstream region of the Hitotsuse River watershed within $2004-2006$.

2. There were 3 types of sources of turbid water in the upstream region of the Hitotsuse River watershed, namely: Type 1 (Collapsed of mountainside), Type 2 (Outflow of collapsed soil), and Type 3 (Waterside erosion).
3. Turbidity Discharge Ratio in the study area was very high in the beginning of the selected period (1994) which indicated the generation of high turbid water in the river stream. The height of the Turbidity Discharge Ratio in this period was caused by a lot of transportation of fine particles from collapsed areas to the river stream.

4. In period of 1995 - 2003, the Turbidity Discharge Ratio tended to decrease due to the lesser amounts of fine particles transported to the river by overland flow.

5. The cumulative discharge about $200 \times 10^{3} \mathrm{~m}^{3} / \mathrm{s}$ is required to reduce the Turbidity Discharge Ratio below 1.

6. Management of the watershed in the upstream region of the Hitotsuse River is required to decrease the Turbidity Discharge Ratio. Appropriate forestry management should be applied in order to reduce the source of turbid water from Type 1, while for Type 2 and Type 3 , a better management on both hillslopes and riverside areas should be conducted.

ACKNOWLEDGMENT: This paper is a part of the research results in cooperation with the Miyazaki Prefecture and the Kyushu Electric Power Co., Inc..

\section{REFERENCES}

1) Harisuseno, D., Sumoto, H., Deguchi, C., Takeda, H., Sugio, S., and Murakami, K.: Relation between reservoir sedimentation and deforested area in the Omaru River watershed, Annual Journal of Hydraulic Engineering, JSCE, Vol. 51, pp.115-120, February, 2007.

2) Sakai, K., Murakami, T., and Kurashige, N.: Surveillance study on turbidity subsidence promotion technology in the Hitotsuse reservoir, Journal of Electric Power Civil Engineering, pp.33-37, May, 2005.

3) Esaki, T., and Mitani, Y., et al.: Research on evaluation methods of turbid material efflux at the upstream of reservoir, Proceeding of Annual Meeting of JSCE Kyushu Branch, pp.183-184, March, 2007.

4) Japanese Geographic Survey Institute.: Digital Map 50m Grid (Elevation) CD-ROM, Japanese Geographic Survey Institute, Tokyo, 1997.

5) Saito, M., Kimura, K., Naito, K., and Sakai, A.: Geology of Siibason District, Geological Survey of Japan, 6-59 (in Japanese), 1996.

6) Sugden, B.D and Woods, S.W.: Sediment production from forest roads in Western Montana, Journal of The American Water Resources Association, Vol. 43, No. 1, pp.193-206, American Water Resources Association, February, 2007.

7) Dongtao, MA., Tianjun, TU., Peng, CUI., and Ruren, LU.: Approach to mountain hazards in Tibet, China, Journal of Mountain Science, Vol. 1 No. 2, pp.143-154, 2004.

(Received September 30, 2007) 